\title{
Gestão do Conhecimento nas Cooperativas
}

\section{Knowledge Management in the Cooperative}

\begin{abstract}
Resumo
Os avanços que norteiam os processos de gestão da tecnologia e da inovação geram necessidade constante de ajuste organizacional no mundo empresarial. Esse cenário é ainda mais marcante no Cooperativismo Solidário, devido as suas diretrizes de interface entre o desenvolvimento social e econômico dos associados. Este artigo apresenta os resultados de uma pesquisa cujo objetivo foi sistematizar o posicionamento das organizações presentes no Cooperativismo da Agricultura Familiar e Economia Solidária, em relação à gestão do conhecimento, verificando-se a partir dos dados coletados, uma ampla fragilidade destas organizações no que se refere à criação e mensuração do conhecimento, sendo destacada a necessidade de qualificação deste procedimento junto aos processos de gestão organizacional.
\end{abstract}

PALAVRAS-CHAVE: Gestão do conhecimento, Controle Social, Cooperativas.

\begin{abstract}
The advances that guide the processes of management technology and innovation generate constant need for organizational adjustment in business. This scenario is even more striking in the Solidarity Cooperative, due to its interface guidelines between the social and economic development of the members. This article presents the results of a study whose objective was to systematize the positioning of these organizations in the Cooperative Family Agriculture and Solidarity Economy in relation to knowledge management, verifying from the data collected, a wide fragility of these organizations on regards the creation and measurement of knowledge, and highlighted the need for qualification of this procedure with the organizational management processes.
\end{abstract}

KEYWORDS: knowledge management, social control, cooperatives.

Recebido: 12/03/2016 Aceito: 11/08/2016

Alcidir Mazutt Zanco e Sandra Maria Coltre ${ }^{2}$

${ }^{1}$ Universidade Estadual do Oeste do Paraná - Campus de Francisco Beltrão - PR, alcidirmz@ yahoo.com.br - Rua Prudente de Albuquerque, 219, Bairro: Cristo Rei - Francisco Beltrão - PR, CEP 85602-509.

${ }^{2}$ Unioeste - Campus Foz Do Iguaçu, sandracutu1@gmail.com. 


\section{Introdução}

$\mathrm{A}$ velocidade imposta pelo mercado global exige das empresas constantes buscas pela inovação e qualificação de suas práticas administrativas, de modo a manter-se com viabilidade organizacional. A evolução provocada pela tecnologia produtiva, comercial e cultural, contribui com o progresso da humanidade, mas também solicita a definição de estratégias, para a criação e gestão do conhecimento empírico e tácito, presentes em nível pessoal e empresarial, das organizações públicas e privadas presentes no cenário contemporâneo.

A Gestão do Conhecimento (GC) constitui-se como estratégia de ampliação da capacidade competitiva das empresas diante do mercado. $\mathrm{Na}$ visão de Nonaka e Takeuchi (1997), nas últimas décadas o conhecimento passou de auxiliar do poder monetário, à sua própria essência. Na nova economia, o conhecimento não é apenas um recurso ao lado dos tracionais fatores de produção, mas, sim o único recurso importante da atualidade. Para Takeuchi e Nonaka (2008), o conhecimento é essencialmente tácito e pessoal, uma vez que está vinculado à subjetividade humana, sendo papel da GC capacitar os indivíduos para instilar e gerenciar o conhecimento, facilitando processos de socialização, externalização, combinação e internalização, garantindo a viabilidade das organizações.

No cooperativismo a GC é um dos processos vinculados às estratégias de educação e capacitação cooperativista, cabendo a esta construir instrumentos de construção e multiplicação do conhecimento adequado à realidade do cooperativismo, como forma de impulsionar e assessorar de forma eficiente gestão das cooperativas, com relação direta com os interesses dos associados. A sociedade cooperativa trabalha de forma pluridimensional com objetivos de ordem econômica e social, o que a torna, a priori, uma organização complexa e distinta de outras formas de organização. Nesse contexto, o papel da educação é atuar equilibradamente na gestão social e empresarial, com vistas a proporcionar crescimento na participação dos cooperados e na profissionalização da gestão singular da organização.

Autores como Schneider (2003) e Singer (2002) defendem que o sucesso empresarial das cooperativas é vinculado a forma como estas trabalham a interface da GC no processo de transmissão da educação. As cooperativas por sua própria natureza associativa são organizadas em função das pessoas, sendo fundamental um trabalho que reforce a educação cooperativista na gestão da cooperativa, com a dupla finalidade de manifestar sua potencialidade, econômica e social. Os processos educativos do cooperativismo são meios pelos quais ocorre a transmissão dos valores, orientados para uma melhor relação e organização do fluxo de informações junto aos associados, ação totalmente vinculada a GC.

Diante da diversidade de cooperativas existente no cenário Brasileiro, neste artigo são estudadas iniciativas de GC desenvolvidas por cooperativas do ramo agropecuário, presentes no Sistema UNICAFES - União de Cooperativas da Agricultura Familiar e Economia Solidária, tendo como fonte de dados o PECSOL - Programa Nacional de Educação do Cooperativismo Solidário, ação desenvolvida anualmente para capacitação de sócios e diretores cooperativistas de todos os Estados do Brasil.

O estudo buscou responder se as cooperativas do sistema UNICAFES orientam suas ações educativas a partir da gestão do conhecimento. $\mathrm{Na}$ primeira parte do estudo é realizada uma revisão de literatura, buscando fundamentar o método de pesquisa, com sistematização do questionário enquanto instrumento de coleta de dados. $\mathrm{Na}$ segunda parte é realizada análise dos resultados, com síntese da interface entre a compreensão desta temática e a situação atual das cooperativas participantes.

\section{O Cooperativismo E A Sua Base Organizacional}

O cooperativismo pode ser reconhecido em diversas fases da civilização, mas é reconhecido formalmente a partir dos confrontos desenvolvidos entre o Capitalismo e o Socialismo. Estes modelos socioeconômicos são marcados por várias diferenças teóricas que orientam sua atuação social. O socialismo defendeu a socialização dos meios de produção como meio para promoção do desenvolvimento. Já o capitalismo tem como objetivo principal a acumulação de capital através 
do lucro, tendo a eficácia econômica como máxima societária.

No século XVIII, a Revolução Industrial fortaleceu o sistema capitalista e solidificando as raízes deste sistema econômico (ABRAMOVAY, 1992). A Revolução Industrial colocou a máquina para fazer o trabalho dos artesãos. O dono da fábrica conseguiu, desta forma, aumentar sua margem de lucro, pois a produção acontecia com mais rapidez. Esse processo foi norteado pelo liberalismo de Adam Smith que defendeu a não intervenção do Estado na economia, fundamentando as bases do capitalismo. Hoje este sistema determina as relações sociais e comerciais da humanidade. A globalização permitiu as corporações produzir e vender seus produtos mundialmente. Os sistemas informatizados possibilitam a circulação e transferência de valores em tempo real, intensificando a concentração dos investimentos e lucros no mundo empresarial (SACHS, 2003).

O socialismo pode ser considerado como único sistema que enfrentou a hegemonia do capital. O surgimento do sistema encontra-se no século XVIII e se caracteriza pela idéia de transformação da sociedade através da distribuição equilibrada de riquezas. Thomas More é considerado o primeiro defensor deste sistema. Para o autor, os homens só poderiam ser iguais no momento em que não existisse concentração de riqueza. (BIALOSKORSKI, 2006)

Destacam-se como autores socialistas os franceses e britânicos, especialmente Robert Owen, Charles Fourier, Pierre-Joseph Produdhon, Louis Blanc e o Conde de Saint-Simon. Esses autores criticaram os excessos de desigualdade provocados pela Revolução Industrial e defendiam reformas como distribuição igualitária de riquezas e a transformação da sociedade em comunidades nas quais a propriedade privada seria abolida, onde as classes sociais vivessem em harmonia ao buscarem interesses comuns (SCHENEIDER, 2003).

Os resultados negativos da Revolução Industrial provocaram o surgimento da organização popular e da Economia Solidária. O Capitalismo fundamentase na busca pelo lucro, geralmente concentrado em poucas pessoas. As organizações que atuam na perspectiva solidária reinvidicam uma gestão emancipadora, desenvolvendo uma matriz oposta à razão instrumental, baseada em resultados
(ABRAMOVAY, 1992).

Existem diferentes autores que se dedicam à conceituação da Economia Solidária e que influenciam diretamente o processo organizacional do Cooperativismo da Agricultura Familiar e Economia Solidária, sendo que os principais são Paul Singer e Euclides Mance. Singer propõe que a Economia Solidária seja uma estratégia de luta contra as desigualdades sociais e o desemprego, utilizando os limites do capitalismo, como alicerces de formas alternativas de organização da produção, numa lógica oposta àquela que rege $\mathrm{o}$ mercado capitalista (SINGER, 2002).

Para Mance, o conceito vai além e agrega a noção não apenas de geração de postos de trabalho, mas sim uma colaboração solidária que visa a construção de sociedades pós-capitalistas, onde se garanta o bem-viver de todas as pessoas. $\mathrm{O}$ autor considera colaboração solidária como um trabalho compartilhado, cujo vínculo recíproco entre as pessoas advém, do sentido moral de corresponsabilidade pelo bem-viver de todos, buscando ampliar o exercício concreto da liberdade (MANCE, 2002).

A Economia Solidária é um projeto de organização socioeconômica presente em diversos Países, com princípios de cooperação, inclusão e desenvolvimento participativo, que orientam a construção de redes de relações econômicas justas e solidárias, entre produtores e consumidores. Essa economia fundamenta a construção de políticas públicas que fomentam a organização dos trabalhadores, resgatando processos que promovam o desenvolvimento e a menor dependência de políticas de assistência social (SINGER, 1998).

Essa Economia toma como pressuposto a defesa de uma economia alternativa ao capitalismo, vista não só uma necessidade material, mas também como ferramenta de transformação social e de opção ideológica. Essa outra economia tem como meta a organização e o empoderamento socioeconômico dos participantes, fortalecendo diversas iniciativas exitosas no setor produtivo e agroindustrial (CUNHA, 2003). A estratégia autogestionária se fundamenta na tese de que as contradições do capitalismo criam oportunidades para o surgimento de organizações econômicas alternativas, com lógica oposta à do modo de produção capitalista. A autogestão retoma a idéia de Rosa Luxemburgo da "Experimentação Social", da 
articulação da idéia de autogestão com as experiências concretas. A sociedade autogestionária se institui e se constrói por si mesma, como um método de transformação social.

A proposta autogestionária tem como característica, a recuperação dos laços de solidariedade já nos processos produtivos, por meio da transparência da gestão, da divisão de poder e dos ganhos, com participação ativa dos cooperativados trabalhadores. A autogestão pode ser considerada o grande diferencial das iniciativas de Economia Solidária. Esta diretriz influenciou de maneira expressiva a organização do novo Cooperativismo brasileiro.

\section{A Educação No Cooperativismo Solidário}

\section{O Cooperativismo é reconhecido como} ferramenta crucial para promoção do desenvolvimento. Grandes partes dos Países desenvolvidos fomentam e utilizam este segmento, como matriz articuladora dos processos de dinamização socioeconômica, valorizando as cooperativas independente de sua fase ou ramo organizacional. No Brasil, este segmento recebe menor nível de valorização e reconhecimento, as ações Governamentais e as Políticas Públicas de fomento, investimentos e de educação, não abordam com intensidade a importância deste setor. Neste contexto as organizações delegam aos processos de educação cooperativa, a missão de provocar conscientização sobre $\mathrm{o}$ ato de cooperar, tendo a difícil tarefa de enfrentar um processo hegemônico marcado pelo Capital.

As ações de educação são responsabilizadas pela formação de novas culturais sociais, produtivas e econômicas, sendo fundamental análise destas metodologias e suas potencialidades diante da diversidade existente no cenário brasileiro. A educação do Cooperativismo Solidário é uma ação desenvolvida pela UNICAFES - União de Cooperativas da Agricultura Familiar, entidade nacional que representa e desenvolve serviços para o fortalecimento das "Cooperativas Solidárias"1. A organização busca fortalecer o Cooperativismo, como instrumento para promoção do

1 Cooperativas Solidárias: Termo definido durante o I Congresso da Unicafes Nacional, realizado em julho de 2005, como sinônimo para a expressão "Cooperativas da Agricultura Familiar e Economia solidária". desenvolvimento com inclusão social, com fundamentos basilares vinculados ás diretrizes de Economia Solidária, tendo como princípios norteadores, as relações de proximidade, a participação popular, o controle social e o empoderamento dos associados diante do seu contexto social.

A base associada neste segmento socioeconômico é formada por pessoas com baixa escolaridade. Grande parcela dos associados possui somente a formação básica, tendo seus conhecimentos fortemente ancorados em processos de educação e formação informal, articulados através de encontros, cursos e intercâmbios realizados em regime de alternância. $\mathrm{O}$ fortalecimento deste público tem gerado várias formas de organização e geração de renda, sendo solicitado as metodologias de educação inovações permanentes nos processos de ensino aprendizagem.

O Sistema de Cooperativas Solidárias é presente em todos os Estados da Nação, articulando 1.200 Cooperativas, presentes em diversos ramos cooperativos. Estes ramos cooperativos possuem formatos e regras diferentes de organização, orientadas pelas instâncias legais, comerciais ou financeiras a que são vinculadas. Estas regras orientam os processos educativos, sendo um agravante aos processos educativos, que necessitam articular processos que integrem a formação doutrinária, técnica e política com foco no empoderamento das lideranças.

Os sete princípios do cooperativismo são as linhas orientadoras para os processos de educação e gestão do conhecimento. Por meio destes as cooperativas levam os seus valores à prática. Estes princípios foram aprovados na fundação da primeira cooperativa e ainda são atuais para os processos de cooperação, sendo orientadores de todos os eixos organizacionais, permeando as ações com: Adesão voluntária e livre; Gestão democrática; Participação econômica dos membros; Autonomia e independência; Educação, formação e informação; Intercooperação e interesse pela comunidade.

Através do princípio vinculado a Educação, formação e informação, as cooperativas promovem a educação dos seus membros, dos representantes eleitos e dos trabalhadores, de forma que estes possam contribuir, eficazmente, para o desenvolvimento das suas cooperativas. De maneira 
geral que não existem nos documentos formais do Cooperativismo Solidário, descrições claras sobre as metodologias e programas de GC que devem ser adotados para realização dos e avaliação do processo educativo, cabendo ás organizações representativas formular, aprovar e executar metodologias apropriadas para que as ações educativas gerem resultados para a viabilidade organizacional, com processos que fomentem a maior organicidade social e econômica dos cooperados.

\subsection{Gestão Do Conhecimento No Cooperativismo}

No Cooperativismo a GC é considerada um método que norteia a capacidade de uma empresa em de criar, disseminar e incorporar o conhecimento, como um processo que amplia organizacionalmente o conhecimento criado pelos indivíduos. O Cooperativismo tem como foco de suas ações o crescimento das pessoas, conforme Takeuchi e Nonaka (2008) o conhecimento só pode ser criado pelos indivíduos, mas estes devem ser apoiados e estimulados intencionalmente pela organização, que proporciona condições necessárias para o seu desenvolvimento.

Conforme estes pensadores a dinâmica da criação do conhecimento é um processo em espiral, que começa no nível individual e se amplia para comunidades de interação que cruzam fronteiras entre seções, departamentos e organizações, sendo necessário criar instrumentos para identificar, gerar, trocar e coletar o conhecimento necessário para a viabilidade organizacional, tendo como fundamento a afirmação de que "na nova economia, o conhecimento não é mais um recurso, mas sim o único recurso significativo atualmente" (NONAKA e TAKEUCHI, 1997, p. 5).

A teoria sobre GC surgiu do conceito de capital intelectual e desenvolveu concepções com base nos estudos sobre a importância dos recursos intangíveis e das competências organizacionais. Os avanços nos sistemas de tecnologia têm provocado enorme aceleração nos processos de criação e GC, instaurando uma nova era nas relações interpessoais e uma nova maneira de gerenciar as pessoas. Neste meio verifica-se que o conhecimento necessita ser visto como o principal ativo estratégico das organizações (FLEURY; OLIVEIRA JÚNIOR,
2001). A GC tem como principal objetivo a criação do conhecimento organizacional, entendido como a capacidade de uma empresa criar um conhecimento, difundi-lo e incorporá-lo a produtos e serviços. Esse processo é a chave para as formas características com que as empresas inovam (NONAKA e TAKEUCHI, 1997).

Augier e Knudsen (2004) defendem que o projeto organizacional das 'organizações do conhecimento' devem estar orientados ao tratamento dos problemas associados à racionalidade limitada e à exposição excessiva aos fluxos de informação. Para Brown e Duguid (2001), as relações que se estabelecem entre organização e conhecimento devem ser estudados na sua dimensão social e na perspectiva de sua aplicação prática. Este artigo se fundamenta na análise social da GC, pois as cooperativas se orientam pela participação das pessoas no desenvolvimento social e econômico dos empreendimentos.

No processo de GC Probst (2002) afirma que a retenção do conhecimento requer mais do que apenas adquiri-lo. A gestão deve nortear a retenção seletiva das informações. É preciso que a organização estruture com cuidado os processos para selecionar, armazenar e atualizar um conhecimento com potencial valor futuro, sob o risco de perder-se essa competência, pois a retenção do conhecimento depende do uso eficiente de meios de armazenagem da organização.

Para Schneider (2003), a estratégia de GC deve refletir a estratégia competitiva da empresa. Os esforços para codificação do conhecimento caracterizam a orientação central das estratégias de GC e promovem substanciais ganhos de produtividade e de satisfação de seus usuários, sendo fundamental investir na estruturação de processos para viabilizar este setor nas organizações.

Para Singer, (2002) a GC deveria se associar estreitamente á técnicas de gestão de pessoas, uma vez que as relações de trabalho, necessariamente, serão afetadas nesse processo. A importância da situação individual no processo de GC reside no fato das pessoas serem o lócus do que se pretende gerir, tornando-as imprescindíveis devendo ser vistas como investimento organizacional.

Para a efetivação do princípio da educação e das ações de avaliação e GC, a legislação cooperativista determina a constituição do Fundo de Assistência 
Técnica Educacional e Social - FATES, constituído por no mínimo $5 \%$ das sobras líquidas apuradas no exercício, que se destina à prestação de assistência aos associados, seus familiares e, quando previsto os estatutos, aos empregados da cooperativa. Esse fundo tem finalidade financeira, sendo um instrumento facilitador para construção de metodologias sustentáveis para desenvolvimento dos programas de educação.

Para aprimorar qualificar a autogestão, o Governo Brasileiro criou, em 1998, o SESCOOP Serviço Nacional de Aprendizagem do Cooperativismo. Órgão do Sistema S, que oferece programas de formação, promoção social e monitoramento ás cooperativas. Este processo formativo foi instalado como ferramenta para fortalecer Cooperativas dos diversos segmentos, no entanto, o SESCOOP somente beneficia as redes de cooperativas filiadas ao Sistema Tradicional através da OCB - Organização das Cooperativas Brasileiras.

A boa gestão de recursos públicos pressupõe não apenas conformidade dos procedimentos adotados com a lei, mas, também, eficácia, eficiência e efetividade das ações, cabendo, por conseguinte, a prestação de contas evidenciarem sob tais aspectos a gestão realizada. Além disso, a boa gestão de recursos públicos requer uma análise de desempenho (análise da eficácia, eficiência, efetividade e economicidade da gestão com relação a padrões administrativos e gerenciais expressos em metas e resultados negociados com a administração superior ou definidos nas leis orçamentárias) e da capacidade dos controles internos de minimizar riscos e evitar falhas e irregularidades (SESCOOP, 2016).

No processo de investigar que elementos devem ser trazidos a discussão, é relevante observar as necessidades dos associados e também permitir que esses colaborem. Pois, para Freire, "os temas, em verdade, existem nos homens, em suas relações com o mundo, referidos a fatos concretos". (FREIRE, 2014, p.137). A educação representa o quinto princípio do cooperativismo e constituí um dos mecanismos fundamentais para atingir $\mathrm{O}$ desenvolvimento econômico e social.

Desde o início da constituição do cooperativismo, a prática da educação cooperativa já existia e era tida como elemento fundamental para a consolidação deste modelo organizacional
(SCHNEIDER, 2010). A educação cooperativa é um mecanismo essencial para construção da identidade cooperativa, seu projeto de sociedade e economia, constitui sua visão sobre a dignidade da pessoa humana, seus valores, princípios e normas. Qualificar os mecanismos de GC parece não ser uma preocupação das organizações, sendo delegada esta missão a pessoas com menor reconhecimento. O cenário das organizações cooperativistas do século XXI solicita posicionamentos inovadores que integrem desafios sociais e econômicos deste segmento (SCHNEIDER, 2010).

A educação e os processos de GC articulam e fomentam a qualificação dos processos de cooperação, contribuindo para a elaboração de uma identidade comum entre os associados. Acredita-se que o exercício de cidadania dos cooperados deva ocorre através do processo educativo, onde essa educação tenha como base o diálogo e a escuta, mas ao mesmo tempo seja problematizadora e libertadora. Este processo solicita momentos de análise sobre o processo educativo (FREIRE, 1999).

Vários autores descrevem sobre a metodologia da educação cooperativista. As concepções mais destacadas afirmam que a educação será viável se o processo educativo for um processo solidário, que inclua também mentalidades abertas, participativas e que compartilhe e monitores seus resultados. Ao mesmo tempo, esta metodologia deve ter por princípio a produção de conhecimento que envolve uma prática política articulada com a proposta educativa solidária aos sujeitos, no sentido de agir para produzir transformações. "Cabe educador a sensibilidade e a competência para fazer ponte entre a inteligência e a experiência vivida" (FREIRE, 1999, p. 44).

Em termos metodológicos, a cooperação pressupõe o exercício permanente da participação, prevendo o empoderamento social para maior presença dos associados no processo cooperativo. A interação entre cooperativa e sócio amplia as possibilidades de conscientização e oportuniza o exercício da cooperação, possibilitando que cada pessoa descubra seus valores e suas potencialidades e se encoraje em colocá-los em prática (MARTINEZ, 2008). Os processos educativos do Cooperativismo Solidário são fundamentados nas raízes da Economia Solidária. Esta linha é uma alternativa para enfrentamento do capitalismo acumulativo, com um processo de retomada de 
valores da democracia, participação e da autogestão.

A educação popular envolve os eixos de problematização, debate, pesquisa, socialização e sistematização, com etapas de formação continuada que oportunizam o desenvolvimento de saberes produzidos coletivamente, nos quais os cooperantes desempenham simultaneamente o papel de educando e educador. "Uma prática educativa que só pode alcançar efetividade e eficácia na medida da participação livre e critica dos educados" (FREIRE, 2006, p. 13).

O Documento Base do IV Congresso da UNICAFES, realizado em outubro do ano de 2014 valida e reforça as ações vinculadas a educação. Os artigos $312-325^{2}$ trabalham pontos específicos ao fortalecimento desta temática, ressaltando a importância das ações educativas para a integração com os associados, para relações sustentáveis com terceiros e para maior viabilidade dos negócios cooperativos, cita-se alguns destes artigos:

Art. 312 - O processo educativo no Cooperativismo Solidário possui caráter emancipatório, pelo qual se busca aumentar as capacidades e o grau de empoderamento das lideranças, fortalecendo as diferentes necessidades do ser humano, estimulando sua participação ativa na cooperativa. Art. 315 - As cooperativas deverão organizar programas educacionais próprios $\mathrm{e}$ colaborar com instituições formais e organizações da sociedade civil que atuem na área da educação, reforçando a ideia da cooperação como instrumento de fortalecimento econômico e social. Art. 223 Esse Cooperativismo deve articular parceria com Escolas e Universidades, para que a temática do Cooperativismo seja abordada junto aos alunos, com temas e ações de educação para cooperação, visando estimular novas formas de organização para a Agricultura Familiar e Economia Solidária.

O cenário das Cooperativas Solidárias justifica a importância da qualificação de programas de GC, com análise permanente de suas atividades, pois este segmento vincula suas ações á educação, valorizando os saberes dos sócios, reconhecendo suas realidades culturais na construção direcionada do conhecimento. Analisar os resultados as estratégias de GC é fundamental para qualificar a

\footnotetext{
${ }^{2}$ Artigos referentes ao eixo educação presentes no Documento Base do IV Congresso da UNICAFES Nacional realizado em Brasília aos 28 de janeiro de 2014.
}

definição dos papéis e responsabilidades vinculados a este princípio do Cooperativismo.

\subsection{Gc No Cooperativismo E A Espiral Do Conhecimento}

O modelo dinâmico de gestão do conhecimento elaborado Nonaka e Takeuchi (2008) tem como pressuposto básico o conhecimento humano criado e expandido por meio da interação social entre o conhecimento tácito e explícito. Essa interação é um processo social que ocorre entre indivíduos, que gera a conversão do conhecimento o expandindo em qualidade e quantidade. Essa transformação do conhecimento tácito em explícito é o alicerce para criação do conhecimento organizacional, podendo ser comparado ás metodologias da alternância utilizadas nas cooperativas como método de correlação entre conhecimento teórico e prático, que fortalecem a conversão do conhecimento pela socialização, externalização, combinação e internalização.

A socialização é um processo de compartilhamento de experiências que leva a criação de modelos mentais ou habilidades técnicas compartilhadas, tendo como base a passagem do conhecimento tácito ao tácito. A externalização é um processo de articulação do conhecimento tácito em conceitos explícitos expressos através de conceitos e hipóteses, essa combinação trabalha a exposição do conhecimento explícito em explícito, sendo um processo de sistematização de conceitos deste sistema de conhecimentos que envolve a combinação de diferentes de conhecimentos. A internalização é o processo de passagem do conhecimento explícito à tácito, é um processo de incorporação do conhecimento sob a forma de modelos mentais que os torna ativos valiosos para o mundo organizacional.

O conhecimento tácito é pessoal, relacionado a um contexto específico tem por dificuldade formalizar-se e comunicar-se, representa o produto da experiência de vida, incluindo elementos cognitivos e práticos. Já o conhecimento explícito ou codificado pode ser transmitido de forma sistemática, por meio da linguagem formal, está relacionado a eventos ou objetos, independente do contexto, apesar das distinções, Nonaka e Takeuchi (1997) não consideram os conhecimentos tácito e explícito como entidades separadas, e sim 
mutuamente complementares.

O conhecimento tácito esta na cabeça das pessoas. Geralmente é difícil de ser formalizado, pois é subjetivo e inerente às habilidades de uma pessoa. No contexto organizacional o importante é que o "conhecimento tácito precisa se tornar explícito; o que não foi dito, precisa ser dito em voz alta; caso contrário, não pode ser examinado, aperfeiçoado ou compartilhado" (NONAKA e TAKEUCHI, 1997).

Conhecimento explícito é aquele formal, claro e fácil de ser comunicado, pode ser formalizados, assim como guardado em bases de dados ou publicações. O conhecimento explícito pode ser adquirido principalmente pela educação e envolve conhecimento dos fatos, portanto, conhecimento explícito é aquele que pode ser codificado em algo formal, podendo ser comunicado e compartilhado. Para que o conhecimento explícito transforme-se em tácito são necessários os processos de socialização, verbalização do conhecimento.

A base de criação do conhecimento organizacional é constituída através do conhecimento tácito, criado e acumulado no nível individual. Este conhecimento tácito é mobilizado e ampliado na organização através da Espiral do Conhecimento, iniciando-se no nível individual, ampliando-se em comunidades de interação. Para Nonaka e Takeuchi (1997) uma empresa criadora de conhecimento não opera em um sistema fechado, mas em um sistema aberto, com um intercâmbio constante de conhecimento com o ambiente externo. A função da organização no processo de criação do conhecimento é fornecer condições ambientais, sociais e tecnológicas que viabilizem a criação do conhecimento em nível organizacional.

Cada indivíduo tem uma percepção diferente acerca daquilo que recebe. Em virtude destas diferentes percepções as organizações passam por momentos de confusão, no entanto estas confusões podem ser fontes de conhecimento. Desafiar os colaboradores acerca destes paradigmas é uma forma eficiente de incentivar a criação do conhecimento num processo contínuo de aprendizagem. Segundo Nonaka e Takeuchi (1997), para a eficiência deste processo são necessárias cinco condições organizacionais para sua implantação:

- A Intenção. Proporciona condições para julgar veracidade de um determinado conhecimento. Sem intenção não é possível julgar o valor da informação ou do conhecimento percebido ou criado. No nível organizacional, a intenção é expressa por padrões que podem servir para avaliar e justificar o conhecimento criado.

-A Autonomia. Amplia a chance de introduzir oportunidades inesperadas e aumenta a possibilidade dos indivíduos se auto motivarem para criar novo conhecimento. Pode ser desenvolvida através dos processos participativos e a partir de uma cultura de confiabilidade.

-A Flutuação do caos criativo. É uma ordem cujo padrão é difícil de prever quanto o caos intencional, mas aumenta a tensão dentro da organização e foca a atenção dos seus membros na definição do problema e resolução da situação.

-A Redundância. A existência de informações que transcendem as exigências operacionais imediatas. Refere-se à superposição intencional de informações sobre a empresa, responsabilidades sobre gerencia e sobre a empresa como um todo.

-A Variedade de requisitos. Diversidade interna que uma organização deve ter para permitir que ela se dê conta da complexidade do ambiente enfrentando os desafios expostos por ele ampliando possibilidades de construção do conhecimento.

Apesar destas condições facilitadoras uma organização não pode criar conhecimento por si mesmo, sem os indivíduos. Portanto, é importante que a organização estimule atividades criadoras de conhecimento e proporcione contextos apropriados para elas, pois o indivíduo é o criador do conhecimento, a organização é o amplificador o conhecimento e os grupos são os sintetizadores do conhecimento, ao combinar várias fontes de conhecimento a organização pode desenvolver competências e capacidades inovadoras (NONAKA e TAKEUCHI, 2008).

As cooperativas contemporâneas utilizam inovações e tecnologias modernas semelhantes às adotadas pelas empresas tradicionais, mas procuram manter a ótica da cooperação e da solidariedade com diretrizes norteadoras do seu processo organizacional. Neste ambiente o elo entre GC e cooperativismo, acontece na sua forma de organização, pois, os associados necessitam ser motivados pelo sentimento de coletividade e de propriedade conjunta, compreensão que precisa ser mantida e fortalecido. Esse sentimento coletivo fornece subsídios para este formato social, sendo 
um mecanismo para apreender os conhecimentos tácitos e explícitos na construção de modelos organizacionais sustentáveis (SERRANO, 2003).

Para Schneider (2003) os valores organizacionais tem forte impacto na criação do conhecimento organizacional. Pode-se citar a autonomia, a realização, o bem-estar e a preocupação com a coletividade, como valores que se relacionam de forma coletiva com fatores de criação $o$ conhecimento, dentre eles o estímulo ao enfretamento de desafios, o processo decisório participativo, o compromisso consciente com a cooperativa são fundamentais na conversão do conhecimento.

O formato da organização cooperativista, por si só, mostra-se como uma forma de administrar os conhecimentos, pois, seus princípios defendem a liberdade, participação e o envolvimento integral dos cooperados. Desta forma o modelo cooperativo e a GC comungam dos mesmos anseios quando fazem referência as estruturas empresariais como organismos capazes de aprender com o ambiente e com suas próprias experiências (SERRANO, 2003).

A educação cooperativista é um princípio do cooperativismo, considerado elemento indispensável da cooperação, porque ela é essencial à existência das cooperativas, ao entendimento e à aplicação prática dos outros princípios. No entanto, verifica-se que não está sendo suficiente o trabalho de educação nas cooperativas. Os administradores estão centrados no financeiro. De certa forma, o que se exalta na teoria, na prática pouco se faz. Schneider (2003) e Oliveira (2006), consideram que a educação cooperativa está sendo esquecida pelos diretores, resultando em baixa participação dos associados nas atividades promovidas.

Oliveira (2006), reforça a necessidade de ser aperfeiçoar a mediação das relações sociais existentes nas organizações, buscando recuperar a cultura e a dinâmica que lhes são próprias. Assim, para que uma cooperativa tenha um processo dinâmico e interativo, ela deve fortalecer um departamento específico, para viabilizar a criação e transmissão de valores e princípios do cooperativismo, ampliando mecanismos de promoção, criação e transmissão do conhecimento.

As organizações que possuem um caráter voluntário, para manter a democracia precisam ser mais permeáveis à introdução de ideias. Essa abertura permite que a participação ocorra de forma contínua, possibilitando a manutenção do interesse dos membros. Esta abordagem permite assegurar o desenvolvimento da capacitação permanente dos cooperados, promovendo um funcionamento mais democrático, permitindo uma flexibilidade e agilidade que semeiem as bases da competitividade das cooperativas (AMODEO, 2006).

Toda atividade que desperta o interesse comprometido dos associados é em si um método de educação. Esta noção se aplica, às diversas atividades de natureza econômica, social, cultural desenvolvidas pelo cooperativismo, mas não se verificam de forma explicita essas técnicas ou instrumentos que possam medir ou avalizar a GC nas Cooperativas, salvo em processos já vinculados a prestação de contas de parcerias articuladas com Universidades ou instâncias Governamentais.

\section{Metodologia}

Este estudo foi realizado através de pesquisa exploratória, sobre a adoção de práticas de gestão do conhecimento no Cooperativismo Solidário. O questionário foi aplicado durante o ano de 2015, com participação de 200 cooperativas presentes em diversas regiões do Brasil. Nesta pesquisa utilizaram-se questões relacionadas à criação, codificação, disseminação e mensuração do conhecimento, buscando verificar a interface entre GC e a viabilidade organizacional das cooperativas.

As práticas de GC formam sistematizadas, avaliando-se as respostas à percepção da aplicação das funções de GC, numa escala de cinco possibilidades: inexistente, baixa, média e ótima. As questões foram respondidas por diretores de Cooperativas localizadas em municípios do interior do País, com vínculos de geração de renda profundamente agrícolas. A pesquisa usou como método de coleta um questionário previamente elaborado e contou com momentos presenciais de interlocução com lideranças de 20 Estados do Brasil, através de reuniões desenvolvidas com o Conselho de Administração da UNICAFES Nacional - União de Cooperativas da Agricultura Familiar e Economia Solidária, os quais representaram percentual do público que participou da pesquisa aplicada durante a execução do Programa de Educação do Cooperativismo Solidário - PECSOL. 
Tabela 01: Estados participantes

\begin{tabular}{|c|c|c|c|}
\hline Região & Estados & Turmas & Participantes \\
\hline \multirow[t]{7}{*}{ Nordeste } & Bahia & 4 Regionais & 100 participantes \\
\hline & Ceará & 1 Estadual & 25 participantes \\
\hline & Pernambuco & 1 Estadual & 28 participantes \\
\hline & Rio Grande do Norte & 1 Setorial & 25 participantes \\
\hline & Sergipe & 2 Regionais & 45 participantes \\
\hline & Maranhão & \multicolumn{2}{|c|}{ Não executado } \\
\hline & Alagoas & \multicolumn{2}{|c|}{ Não executado } \\
\hline \multirow[t]{4}{*}{ Norte } & Pará & 1 Regional & 20 participantes \\
\hline & Rondônia & 1 Estadual & 35 participantes \\
\hline & Amazonas & 1 Estadual & 25 participantes \\
\hline & Tocantins & 1 Setorial & 20 participantes \\
\hline \multirow[t]{3}{*}{ Centro Oeste } & Mato Grosso & 2 Regionais & 45 participantes \\
\hline & Mato Grosso do Sul & 2 Setoriais & 40 participantes \\
\hline & Goiás & 2 Regionais & 50 participantes \\
\hline \multirow[t]{3}{*}{ Sudeste } & Rio de Janeiro & 1 Regional & 28 participantes \\
\hline & Espírito Santo & 1 Estadual & 25 participantes \\
\hline & Minas Gerais & 2 Regionais & 52 participantes \\
\hline \multirow[t]{3}{*}{ Sul } & Paraná & 7 Regionais & 170 participantes \\
\hline & Santa Catarina & 4 Regionais & 100 participantes \\
\hline & Rio Grande do Sul & 4 Regionais & 100 participantes \\
\hline
\end{tabular}

O questionário foi organizado com 4 (quatro) blocos de perguntas. O primeiro bloco contém 3 (três) questões referente ao processo de criação do conhecimento. O segundo bloco contém 2 (duas) questões referente ao processo de codificação do conhecimento. O terceiro bloco contém 3 (três) questões referente ao processo de multiplicação do conhecimento e o quarto bloco contém 2 (duas) questões referente ao processo de mensuração do conhecimento nas cooperativas participantes.

Além do questionário foram sistematizados dados do programa já presentes na UNICAFES, realizando interface entre os resultados da pesquisa sobre GC e a estrutura operacional existente nas cooperativas, qualificando a análise sobre a possibilidade de concretização das ações. $\mathrm{O}$ conjunto de dados foi tratado por distribuição de frequência e analisados descritivamente.

\section{Resultados E Discusão}

Participaram da pesquisa sobre GC no Cooperativismo Solidário 200 Cooperativas Agropecuárias filiadas ao Sistema UNICAFES. O estudo evidenciou que $70 \%$ (setenta porcento) das cooperativas participantes apresentam dificuldades no gerenciamento dos seus negócios, especialmente nas questões vinculadas à GC. Este fato foi declarado e reafirmando por vários diretores, mas justificado pelo fato deste movimento ter suas ações fundamentadas na promoção do desenvolvimento com inclusão social, mas nem sempre 
fundamentado em diretrizes de viabilidade comercial.

Na primeira reunião presencial com o Conselho Administrativo da UNICAFES, realizou-se apresentação do objetivo da pesquisa, buscando facilitar a interlocução com os participantes. $\mathrm{Na}$ sequência direcionou-se uma pergunta sobre a importância da educação e GC nas cooperativas, com resposta positiva dos participantes, mas, quando questionados sobre os mecanismos utilizados para sistematização dos resultados da educação e da GC, poucos souberam responder, destacando-se que nas cooperativas agropecuárias ainda são poucas as iniciativas presentes de GC.

O primeiro bloco de questões abordou questões sobre o processo de criação do conhecimento. Para $75 \%$ dos entrevistados as cooperativas desenvolvem ações educativas para criação do conhecimento pessoal e organizativo. Na mensuração da qualidade das ações, $20 \%$ consideraram as ações como ótimas e $55 \%$ dos participantes como média, sendo fortalecida a importância da educação, para criação ou geração do conhecimento no Cooperativismo Solidário.

Quadro 1 - Processo de criação do conhecimento

\begin{tabular}{|c|c|c|c|}
\hline Inexistente & Baixa & Média & Ótima \\
\hline $10 \%$ & $15 \%$ & $55 \%$ & $20 \%$ \\
\hline
\end{tabular}

Fonte: PECSOL - dados coletados em 2015.

No segundo bloco de perguntas abordaram-se questões relacionadas aos procedimentos internos realizados para captura do conhecimento. Os resultados da pesquisa revelam preocupação das cooperativas quanto ao conhecimento adquirido e quanto á aplicabilidade dos conhecimentos no campo prático da organização, pois $68 \%$ dos entrevistados considera inexistente, baixo ou médio a captura do conhecimento pelos associados e pelas cooperativas, gerando organizações com pouca inovação, com baixo índice de crescimento social e econômico.

Quadro 2 - Processo de captura do conhecimento

\begin{tabular}{|c|c|c|c|}
\hline Inexistente & Baixa & Média & Ótima \\
\hline $13 \%$ & $25 \%$ & $30 \%$ & $32 \%$ \\
\hline
\end{tabular}

Fonte: PECSOL - dados coletados em 2015.
O terceiro bloco de questões abordou questões sobre os procedimentos utilizados na disseminação do conhecimento. Os procedimentos mais citados destacam que todas as cooperativas realizam ações para disseminação do conhecimento através de palestras, cursos, seminários, reuniões e programas de rádio, mas $71 \%$ dos entrevistados não verifica uma estratégia clara para multiplicação da GC, destacando esta ação como mais um processo corriqueiro e não articulado com as reais demandas organizacionais dos associados e do conselho administrativo das cooperativas.

Quadro 3 - Processo de multiplicação do conhecimento

\begin{tabular}{|c|c|c|c|}
\hline Inexistente & Baixa & Média & Ótima \\
\hline $11 \%$ & $27 \%$ & $33 \%$ & $29 \%$ \\
\hline
\end{tabular}

Fonte: PECSOL - dados coletados em 2015.

No quarto bloco de questões se buscou verificar o quanto as cooperativas conseguem mensurar o conhecimento. Os resultados revelam baixo nível de mensuração do conhecimento. Dos entrevistados $65 \%$ considera que o processo de mensuração só pode ser percebido na vivência dos diretores, pois não existem de forma perceptível indicadores que possam mensurar o conhecimento acumulado pelos associados das cooperativas no processo organizacional e geralmente mensuração tem como único foco a manutenção da viabilidade da cooperativa.

Quadro 4 - Processo de mensuração do conhecimento

\begin{tabular}{|c|c|c|c|}
\hline Inexistente & Baixa & Média & Ótima \\
\hline $12 \%$ & $26 \%$ & $27 \%$ & $35 \%$ \\
\hline
\end{tabular}

Fonte: PECSOL - dados coletados em 2015.

Os quatro blocos de questões revelam que grande parte dos participantes demonstra pouco conhecimento sobre as atividades de GC. Verificando-se que os processos existentes, estão na mente de algumas pessoas e não em sistemas que automatizam estes processos permitindo o seu crescimento. Isso faz com que estas iniciativas se tornem reféns de gerentes ou coordenadores administrativos, além de impossibilitar que este 
conhecimento cresça institucionalmente com os cooperados e com a estrutura organizacional da cooperativa. Essa baixa cultura de valorização do conhecimento institucional é apontada por várias pesquisas como uma das causas da baixa organicidade no cooperativismo, gerando uma sociedade de pessoas distante dos seus sócios (as pessoas fundadoras da organização). Concentrando as atividades desta sociedade de pessoas em procedimentos administrativos, mais vinculados aos negócios econômicos do que a cooperação social.

Muitos pontos podem ser causa destes limites organizacionais. Destacam-se alguns dados presentes nos arquivos dos programas de formação da UNICAFES, que podem considerados empecilhos na qualificação da GC nas cooperativas locais e nas redes regionais de cooperação dos diversos ramos cooperativos:

Estratégia institucional. A GC organizacional só pode ser avaliada quando se implanta uma estratégia de gestão institucional nas cooperativas, mas as Cooperativas estudadas geralmente trabalham com um quadro de funcionários enxuto e as pessoas dedicam tempo integral ás atividades rotineiras. Neste ambiente a GC fica relegada a segundo plano, tornando-se mais uma ação operacional não estratégica e sem condições de regir os processos de criação e multiplicação do conhecimento. Do total de cooperativas estudadas $73 \%$ não possuem estrutura e recursos humanos suficiente para gestão de suas iniciativas produtivas, comerciais e sociais, gerando consequentes falhas na construção de estratégias para a viabilidade social, cultural e econômica.

Quadro 5 - Recursos humanos para gestão interna

\begin{tabular}{|c|c|c|c|}
\hline Inexistente & Baixa & Média & Ótima \\
\hline $28 \%$ & $26 \%$ & $19 \%$ & $27 \%$ \\
\hline
\end{tabular}

Fonte: PECSOL - dados coletados em 2015.

Sistema gestão. A tecnologia tem um papel fundamental em todo processo da GC, possibilitado que o processo organizacional seja fácil, autogestionário e realizado pelos sócios. Esse se destacou como problema, pois as Cooperativas Solidárias, não têm profissionais vinculados a informação e geralmente não utilizam instrumentos tecnológicos como softwares para GC, limitando-se ao arquivo simples de certificados de cursos que comprovam a participação dos sócios vinculados aos cargos diretivos. Destaca-se que $78 \%$ das cooperativas não utilizam as ferramentas on line para a GC.

Quadro 6 - Utilização de ferramentas

\begin{tabular}{|c|c|c|c|}
\hline Inexistente & Baixa & Média & Ótima \\
\hline $26 \%$ & $28 \%$ & $24 \%$ & $22 \%$ \\
\hline
\end{tabular}

Fonte: PECSOL - dados coletados em 2015.

Rotatividade dos funcionários. A instabilidade das Cooperativas da Agricultura Familiar e Economia Solidária gera alta rotatividade de funcionários, as mudanças no cenário econômico, a competição global e as mudanças rápidas no mercado, dificultam ainda mais a viabilidade destas organizações, tornando a GC um processo bastante complicado. A rotatividade dos funcionários concentra o conhecimento nas figuras diretivas, destacando-se que somente $36 \%$ dos recursos humanos das cooperativas atuam nestas por mais de 3 anos consecutivos.

Quadro 7 - Rotatividade dos funcionários

\begin{tabular}{|c|c|c|c|}
\hline 0 ANO & 1 ANO & 2 ANOS & 3 ANOS \\
\hline $20 \%$ & $27 \%$ & $17 \%$ & $36 \%$ \\
\hline
\end{tabular}

Fonte: PECSOL - dados coletados em 2015.

Relação comercial com os sócios. As cooperativas têm como objetivo existencial o atendimento ás necessidades específicas dos associados. Traduzir as necessidades dos associados envolve um processo de criação e desenvolvimento do conhecimento, com forte processo de interface comercial. Este fato é constatado como um grande limite na GC das cooperativas, pois $38 \%$ dos associados demonstram-se insatisfeitos com as relações comerciais estabelecidas neste segmento.

Quadro 7 - Satisfação com relações comerciais

\begin{tabular}{|c|c|c|c|}
\hline Ruim & Baixo & Médio & Ótimo \\
\hline $14 \%$ & $22 \%$ & $26 \%$ & $38 \%$ \\
\hline
\end{tabular}

Fonte: PECSOL - dados coletados em 2015.

Segundo Nonaka e Takeuchi (1997), para eficiência da GC são necessárias algumas condições básicas nas organizações, destacam-se iniciativas 
que precisam ser amadurecidas nas cooperativas estudadas: Intenção - Padrões para avaliar e justificar o conhecimento criado; Autonomia Processos participativos instalados a partir de uma cultura de confiabilidade; Flutuação do caos criativo - Atenção coletiva na definição do problema e resolução; Redundância - Superposição de informações com foco na inovação; Variedade de requisitos - Enfretamento coletivo aos desafios com abertura para construção do conhecimento. Estas iniciativas são perceptíveis nas cooperativas agropecuárias, mas possuem um formato que solicita qualificação.

No Sistema UNICAFES o ramo crédito, representado pelas cooperativas CRESOL, destacase como único ramo que apresenta um método para GC. Este ramo utiliza um sistema on line para arquivo e gerenciamento das ações realizadas. Todos os diretores, sócios e funcionários são convidados a participar de diversos programas de educação, como o Programa Agentes de Desenvolvimento, Um Olhar para o Futuro, Formação de formadores, entre outros, prevendo formatação de um currículo pessoal, mas nem mesmo nas cooperativas de crédito verifica-se um método claro de criação, codificação, disseminação e mensuração do conhecimento.

A UNICAFES desenvolve um sistema de ranking social, com o objetivo de medir as atividades sociais desenvolvidas pelas cooperativas, mas esta iniciativa também não pode ser considerada um método de GC. Este limitador pode ser considerado um dos fatores que tornam perceptíveis possíveis causas de problemas na sustentabilidade deste modelo organizacional, anunciando a necessidade de instauração de processos de inovação pessoal e organizacional nas Cooperativas da Agricultura Familiar e Economia Solidária.

Em resposta a pergunta do estudo, verifica-se que embora o cooperativismo tenha a educação com um princípio executado via recursos do FATES e do SESCOOP, as cooperativas ainda não desenvolveram métodos de GC coletivos. Os sistemas cooperativos mais sólidos, presentes na OCB já instituíram ferramentas para medir a aplicação dos programas de formação, como um método para monitorar a aplicação dos recursos destinados a esta finalidade, mas ainda não existem métodos de GC estruturados nas cooperativas estudadas.

Esse contexto não diminui a positividade deste segmento, pois o Cooperativismo Solidário alimenta suas estratégias alternativas de organização, nas afirmações e defesas ideológicas da Economia Solidária. A proposta autogestionária tem como fundamento a ação socialista e como horizonte $\mathrm{o}$ princípio da autogestão, como alternativa organizacional. $\mathrm{O}$ princípio da autogestão tem por desafio a criação de formas de poder popular, sendo necessário desenvolver formas de democracia organizacional, associadas a novas formas do processo democrático na economia, na educação e na cultura de gestão do conhecimento cooperativista.

\section{Conclusão}

Os resultados obtidos confirmam a presença de funções de GC formais e informais no Cooperativismo Solidário, destacando-se a função mensuração do conhecimento como formalmente presente, porém com certa neutralidade no que se refere à sua institucionalização, merecendo uma pesquisa mais profunda em relação ao seu nível de desenvolvimento.

A fundamentação teórica da pesquisa confirmou que o cooperativismo tem como princípio existencial a transparência, a participação livre e democrática, por isto a maioria participantes acreditam que o cooperativismo é importante para o desenvolvimento equilibrado da sociedade, mas a pesquisa demonstra que a GC nas cooperativas, quando existente, encontra-se concentrada nas mãos de poucas pessoas, diretores ou funcionários que muitas vezes inconscientemente, concentram e dificultam formas de acesso ao conhecimento.

A pesquisa revelou a necessidade de se implantar práticas específicas para a construção de indicadores, processos e práticas para GC. Podendo-se admitir a existência de diversas frentes com foco no empoderamento dos diretores para criação e multiplicação do conhecimento, no entanto, devido aos baixos resultados alcançados pelas propostas em execução, afirma-se a necessidade de revisão das propostas existentes, buscando análise mais qualificada, particularmente no que se refere aos mecanismos de conversão do conhecimento nas cooperativas. 


\section{Referências}

ABRAMOVAY, R. Paradigmas do capitalismo agrário em questão. São Paulo: Hucitec, 1992.

AMODEO, N. B. P. Contribuição da educação cooperativa nos processos de desenvolvimento rural. In: AMODEO, N. B. P; ALIMONDA, H. (Org.). Ruralidades: capacitação e desenvolvimento. Viçosa: UFV, 2006.

ANDION, Carolina. A gestão no campo da economia solidária: particularidades e desafios. RAC, v. 9, n. 1, Jan./Mar. 2005.

AUGIER, M.; KNUDSEN, T. The architecture and design of the knowledge organization. Journal of Knowledge Management, v. 8, n. 4, p. 6-20, 2004.

BIALOSKORSKI NETO, S. Economia e gestão de organizações cooperativas. 2 . ed. São Paulo: Atlas, 2012.

BIALOSKORSKI, S. Aspectos Econômicos das Cooperativas. Belo Horizonte: Mandamentos, 2006.

BRASIL. Decreto no 3.017, de 6 de abril de 1999. Aprova o Regimento do Serviço Nacional de Aprendizagem do Cooperativismo - SESCOOP. Diário Oficial [da] República Federativa do Brasil, Poder Legislativo, Brasília, DF, 6 abr. 1999. Disponível: <http:// www.planalto.gov.br/ccivil_03/decreto>. Acesso em: 21 jun. 2016.

BROWN, J. S.; DUGUID, P. Knowledge and organization: A social-practice perspective. Organization Science, v. 12, n. 2, p. 198-213, 2001.

CHIAVENATO, I. Gestão de pessoas: O novo papel dos recursos humanos nas organizações. $3^{\mathrm{a}}$ ed. Rio de Janeiro: Elsevier, 2010.

DESROCHE, H. Sobre o projeto cooperativo: democracia, animação e ética. In: DRUCKER, P. F. Sociedade pós capitalista. 2a. ed. São Paulo, Pioneira, 1994.
FLEURY, M. T. L.; OLIVEIRA JUNIOR, M. M. Gestão estratégica do Conhecimento: integrando aprendizagem, conhecimento e competências. São Paulo: Atlas, 2001

OCB. Organização das Cooperativas Brasileiras. Promoção e defesa dos interesses das cooperativas. Disponível em: <http:// www.ocb.org.br/site/ocb/>. Acesso em: 09 jun. 2016.

OCB. Organização do Quadro Social em Cooperativas. Brasília: Educação e Capacitação Cooperativista do Sistema OCB, 2014.

OLIVEIRA, Djalma Pinho. Rebouças de Planejamento estratégico: conceitos, metodologia e prática. 6 ed. São Paulo: Atlas, 2006.

Organização das Nações Unidas para Alimentação e Agricultura (FAO). Cooperativas agrícolas, a chave para reduzir a fome a a pobreza. Disponível em <https://www.fao.org.br/cacrfp.asp >. Acesso em: 09 jun. 2016.

PINHO, D. B. A educação cooperativa nos anos 2000 valorizando a cidadania brasileira. In: SCHNEIDER, J. O. (Org.). Educação cooperativa e suas práticas. Brasília: SESCOOP. 2003.

PROBST, Gilbert.; RAUB, Steffen.; ROMHARDT, Kai. Gestão do conhecimento: os elementos construtivos do sucesso. Porto Alegre: Bookman, 2002.

SCHNEIDER, J. O. Pressupostos da educação cooperativa: a visão de sistematizadores da doutrina do cooperativismo. In: SCHNEIDER, José Odelso. Educação cooperativa e suas práticas. Brasília: UNISINOS, 2003.

SERRANO, Antônio Carlos. Gestão do Conhecimento. Editora FCA, 2003.

SILVA, S. L. Informação e competitividade: a contextualização da gestão do conhecimento nos processos organizacionais. Ciência da 
Informação, 2002.

SINGER, P. A recente ressurreição da economia solidária no Brasil. Rio de janeiro: Civilização Brasileira, 2002.

TAKEUCHI, H.; NONAKA, I. Criação do conhecimento na empresa: como as empresas japonesas geram a dinâmica de inovação. Rio de Janeiro: Campus, 1997.

TAKEUCHI, H; NONAKA, I. Gestão do conhecimento. Porto Alegre: Bookman, 2008.

TERRA, J. C. C. Gestão do conhecimento: o grande desafio empresarial. São Paulo: Negócio, 2007.

UNICAFES - União de Cooperativas da Agricultura Familiar e Economia Solidária. Programa Nacional de Educação do Cooperativismo Solidário. Brasília, 2014. 
